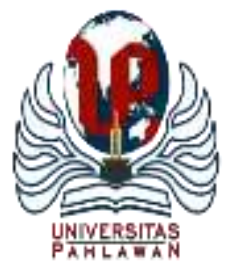

Edukatif : Jurnal Ilmu Pendidikan Volume 4 Nomor 1 Tahun 2022 Halm 390 - 398

EDUKATIF: JURNAL ILMU PENDIDIKAN

Research \& Learning in Education

https:/ledukatif.org/index.php/edukatif/index

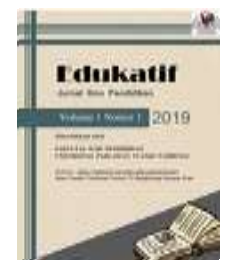

\title{
Implementasi Pendekatan Saintifik dalam Pembelajaran IPA di Indonesia : Suatu Meta-Analisis
}

\author{
Mega Elvianasti ${ }^{1}$, Lufri $^{2}$, Asrizal $^{3}$, Rikizaputra $^{4 凶}$ \\ Pendidikan Biologi, Universitas Muhammadiyah Prof. Dr. Hamka, Jakarta, Indonesia ${ }^{1}$, Pendidikan IPA, \\ Universitas Negeri Padang, Indonesia ${ }^{2,3}$, Pendidikan Biologi, Universitas Lancang Kuning, Riau, Indonesia ${ }^{4}$ \\ E-mail : megaelvianasti@uhamka.ac.id ${ }^{1}$, lufri_unp@yahoo.com ${ }^{2}$, asrizal@fmipa.unp.ac.id $^{3}$, \\ rikizaputra@unilak.ac.id ${ }^{4}$
}

\begin{abstract}
Abstrak
Tujuan dalam penelitian ini adalah mengukur effect size sejumlah artikel penelitian eksperimen yang menerapkan pendekatan saintifik dalam pembelajaran IPA di Indonesia serta pada sejumlah artikel yang mengkombinasikan pendekatan saintifik dengan model pembelajaran dan media pembelajaran. Summary effect yang diperoleh sebesar 0,994 yang dikategorikan tinggi sehingga dapat diinterpretasikan bahwa implementasi pendekatan saintifik dalam pembelajaran IPA signifikan dan efektif. Dari hasil penelitian diperoleh bahwa pendekatan saintifik dapat diterapkan pada semua jenjang sekolah dari taman kanak-kanak sampai perguruan tinggi. Implementasi pendekatan saintifik dapat meningkatkan hasil belajar siswa baik dari segi kognitif, kreativitas, pemecahan masalah. Pendekatan saintifik merupakan salahsatu strategi dalam pembelajaran IPA yang bertujuan untuk membantu siswa secara aktif mengonstruksi pengetahuan berdasarkan kegiatan ilmiah. Penelitian ini dapat menjadi rujukan bagi pendidik bahwa pendekatan saintifik sesuai dengan karakteristik siswa di semua tingkat dan merupakan wujud dari implementasi kurikulum 2013.
\end{abstract}

Kata Kunci: Pendekatan saintifik, Pembelajaran IPA, Meta-analisis

\begin{abstract}
The purpose of this study is to measure the effect size of a number of experimental research articles that apply a scientific approach to science learning in Indonesia. In a number of articles that combine a scientific approach with learning models and learning media. The summary effect obtained is 0.994 which is categorized as high so it can be interpreted that the implementation of the scientific approach in science learning is significant. From the results of the study, it was found that the scientific approach can be applied to all levels of school from kindergarten to university. The implementation of a scientific approach can improve student learning outcomes both in terms of cognitive, creativity, problem solving, etc. The scientific approach is one of the strategies in science learning that aims to help students actively construct knowledge based on scientific activities. This research can be a reference for educators that the scientific approach is in accordance with the characteristics of students at all levels and is a manifestation of the implementation of the 2013 curriculum.
\end{abstract}

Keywords: Scientific Approach, Science Learning, Meta-analysis

Copyright (c) 2022 Mega Elvianasti, Lufri, Asrizal, Rikizaputra

$\square$ Corresponding author

Email : rikizaputra@unilak.ac.id

DOI : https://doi.org/10.31004/edukatif.v4i1.1819

ISSN 2656-8063 (Media Cetak)

ISSN 2656-8071 (Media Online)

Edukatif : Jurnal Ilmu Pendidikan Vol 4 No 1 Tahun 2022 p-ISSN 2656-8063 e-ISSN 2656-8071 
391 Implementasi Pendekatan Saintifik dalam Pembelajaran IPA di Indonesia : Suatu Meta-Analisis Mega Elvianasti, Lufri, Asrizal, Rikizaputra

DOI: https://doi.org/10.31004/edukatif.v4i1.1819

\section{PENDAHULUAN}

IPA merupakan disiplin ilmu yang sangat erat kaitannya dengan kehidupan sehari-hari siswa. Pengetahuan berupa fakta, prinsip, konsep serta proses penyelidikan dan sikap ilmiah menjadi karakteristik dalam IPA. Nahdi et al. (2018) mengungkapkan bahwa pembelajaran IPA memiliki tujuan agar siswa memahami konsep IPA yang berkaitan dengan gejala alam dan dapat diterapkan dalam kehidupan sehari-hari. Pembelajaran IPA yang bermakna diyakini dapat mengaktifkan siswa dan meningkatkan penguasaan konsep. Banyak permasalahan yang dihadapi dalam ruang lingkup pembelajaran IPA, misalnya : pembelajaran IPA yang masih menggunakan metode konvensional (berpusat pada guru) dan minat siswa yang masih rendah karena siswa kurang memahami istilah asing dalam IPA (Imanuel, 2015). Makna dari istilah asing tersebut seyogyanya sangat dekat dengan keseharian siswa sehingga apabila pembelajaran IPA dapat dikaitkan dan dibawa secara kontekstual/nyata tentu akan meningkatkan hasil belajar siswa.

Pendekatan saintifik disebut juga dengan pendekatan ilmiah. Pendekatan ini dapat digunakan oleh guru dalam pembelajaran IPA. Pendekatan saintifik pertama kali diperkenalkan pada Abad ke-19 dalam pembelajaran sains di Amerika melalui penekanan pada tata cara laboratorium formal yang menuju pada fakta-fakta ilmiah (Hodson, 1996 ; (Rudolph, n.d.). Pendekatan saintifik serangkaian kerja yang dilakukan oleh ilmuwan dalam mempelajari alam dan menyampaikan hasil analisis berdasarkan bukti dan fakta ilmiah yang diamati (Chen, 2010; Gerber, Ketelhut \& Schifter, 2011 ; Hwang et al., 2012). Pendekatan ini lebih mengutamakan keaktifan dan partisipasi siswa sehingga siswa dapat mengembangkan kemampuan dasar seperti keterampilan komunikasi, critical thinking, dan problem solving (Lazányi, 2012).

Proses pembelajaran IPA dengan menggunakan pendekatan saintifik dirancang agar siswa dapat aktif melakukan konstruksi terhadap konsep, hukum-hukum atau prinsip melalui serangkaian langkah, yaitu pengamatan atau observasi guna mengidentifikasi masalah, perumusan masalah, pengajuan hipotesis, pengumpulan data, menyimpulkan, dan mengomunikasikannya. Kondisi pembelajaran yang diharapkan bukan hanya siswa diberi tahu melainkan melalui proses mencari tahu dari berbagai sumber melalui kegiatan observasi (Wijayanti, 2014).

Di Indonesia pendekatan saintifik sangat erat kaitannya dalam implementasi kurikulum 2013. Tujuan dari kurikulum 2013 adalah mendukung siswa agar mampu melaksanakan kegiatan mengobservasi, menanya, menalar, serta mengomunikasikan apa yang telah mereka peroleh dari hasil penyelidikan (Anwar, 2014). Kurikulum 2013 berorientasi pada meningkatnya dan penyeimbangan antara kompetensi kognitif, afektif, dan psikomotorik (Ikhsan \& Hadi, 2018). Pendekatan saintifik digunakan agar siswa mudah dalam memahami sains dan dapat menghilangkan miskonsepsi siswa. Pada pelaksanaannya kurikulum ini menggunakan pendekatan saintifik, yaitu : 1) mengamati, 2) menanya, 3) menghasilkan hipotesis dan prediksi, 4) eksperimen/ pengujian hipotesis, 5) meringkas/ menganalisis data untuk menarik kesimpulan, 6) mengomunikasikan penemuan dan proses kepada orang lain, 7) mengidentifikasi pertanyaan baru (Gelman \& Brenneman, 2004). Dengan adanya implementasi pendekatan saintifik diharapkan dapat meningkatkan hasil belajar siswa, keterampilan 4C, pemecahan masalah dan keterampilan proses sains siswa.

Penelitian terdahulu yang dilakukan oleh Putri (2020) dan Aulia et al. (2020) dengan metode yang sama terhadap implementasi pendekatan saintifik hanya berfokus pada tingkat SD dan SMP, namun dalam penelitian ini bertujuan dalam mengukur effect size sejumlah artikel penelitian eksperimen yang menerapkan pendekatan saintifik dalam pembelajaran IPA di Indonesia pada semua tingkat pendidikan dimulai dari taman kanak-kanak sampai perguruan tinggi, dan difokuskan pada sejumlah artikel yang mengombinasikan pendekatan saintifik dengan model pembelajaran dan media pembelajaran. 
392 Implementasi Pendekatan Saintifik dalam Pembelajaran IPA di Indonesia : Suatu Meta-Analisis Mega Elvianasti, Lufri, Asrizal, Rikizaputra

DOI: https://doi.org/10.31004/edukatif.v4i1.1819

\section{METODE PENELITIAN}

Penelitian ini menggunakan pendekatan kuantitatif dengan jenis penelitian meta-analisis. Metode penelitian ini merupakan sintesis ilmiah secara kuantitatif dari beberapa hasil penelitian, sintesis penelitian ini diperkenalkan pada tahun 1970-an. Meta-analisis telah memiliki efek revolusioner di banyak bidang ilmu dengan membangun praktik berbasis bukti. Tujuannya adalah untuk menilai bukti kefektifan untuk masalah tertentu atau hubungan sebab akibat yang dihipotesiskan untuk suatu kondisi tertentu, seringkali dalam jumlah studi yang relatif kecil atau kurang dari 25 (Gurevitch et al., 2018). Langkah-langkah dalam penelitian ini adalah :

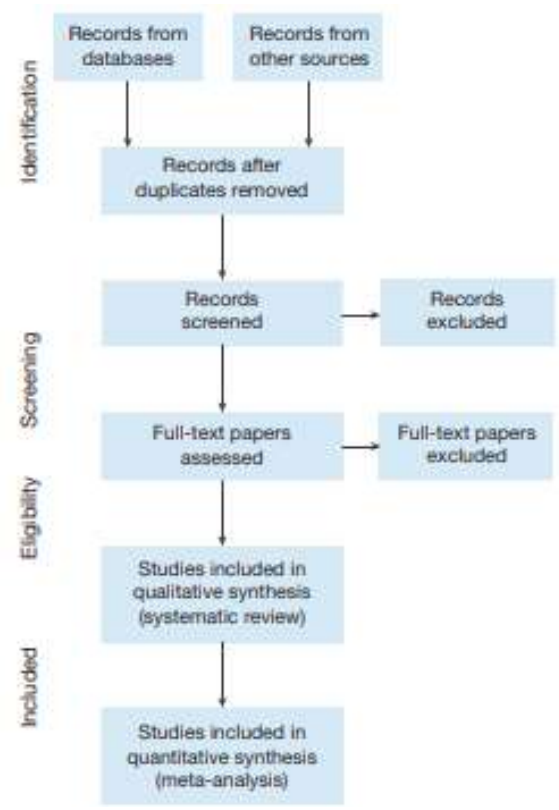

Gambar 1. Diagram alir PRISMA 12 (Gurevitch et al., 2018)

Diagram alir di atas menggambarkan aliran informasi (jumlah publikasi yang relevan) pada empat tahap sistematika yaitu: proses peninjauan (identification, screening, eligibility, dan included). Sampel dalam penelitian ini di ambil sebanyak 19 studi dari 14 artikel ilmiah dari jurnal nasional terakreditasi SINTA dan jurnal internasional dengan rentang publikasi dari tahun 2015-2021. Hasil penelitian lebih mengutamakan pada implementasi pendekatan saintifik dalam pembelajaran IPA di Indonesia. Menurut Banas et al. (2016) ada dua fungsi meta-analisis, yaitu: 1. Menghitung ukuran efek rata-rata dari studi yang dianalisis, 2. Menguji variabel moderat yang dapat menjelaskan temuan yang tidak konsisten dalam penelitian.

Lembar tabulasi digunakan sebagai instrumen penelitian, setelah data di input kemudian dianalisis menggunakan Excel dan OpenMEE kemudian data di crosscheck dengan menggunakan rumus effect size menurut (Cohen, 1981).

Tabel 1. Kategori Effect Size menurut (Cohen, 1981)

\begin{tabular}{lll}
\hline No & ES & Kategori \\
\hline 1 & $0,00 \leq \mathrm{ES} \leq 0,20$ & Abaikan \\
2 & $0,20<\mathrm{ES} \leq 0,50$ & Rendah \\
3 & $0,50<\mathrm{ES} \leq 0,80$ & Sedang \\
4 & $0,80<\mathrm{ES} \leq 1,30$ & Tinggi \\
5 & $1,30 \leq \mathrm{ES}$ & Sangat Tinggi \\
\hline
\end{tabular}


393 Implementasi Pendekatan Saintifik dalam Pembelajaran IPA di Indonesia : Suatu Meta-Analisis Mega Elvianasti, Lufri, Asrizal, Rikizaputra

DOI: https://doi.org/10.31004/edukatif.v4i1.1819

\section{HASIL DAN PEMBAHASAN PENELITIAN}

Sebanyak 19 studi dari 14 artikel dianalisis dan dihitung effect sizenya menggunakan OpenMEE, software ini merupakan perangkat lunak statistik open access dan open source pertama untuk meta-analisis (Wallace et al., 2017) sehingga diperoleh effect size untuk masing-masing studi sebagai berikut :

Tabel 2. Effect size masing-masing studi

\begin{tabular}{cccc}
\hline No. & Kode Artikel & Effect Size & Kategori \\
\hline 1 & K1 & 1,07 & Tinggi \\
\hline 2 & K2 & 0,018 & Abaikan \\
\hline 3 & K3 & 0,193 & Abaikan \\
\hline 4 & K4 & 1,782 & Sangat Tinggi \\
\hline 5 & K5 & 1 & Tinggi \\
\hline 6 & K6 Studi ke-1 & 0,985 & Tinggi \\
\hline 7 & K6 Studi ke-2 & 0,84 & Tinggi \\
\hline 8 & K7 & 0,438 & Rendah \\
\hline 9 & K8 Studi ke-1 & 0,774 & Sedang \\
\hline 10 & K8 Studi ke-2 & 1,345 & Sangat Tinggi \\
\hline 11 & K8 Studi ke-3 & 1,578 & Sangat Tinggi \\
\hline 12 & K9 & 1,022 & Tinggi \\
\hline 13 & K10 Studi ke-1 & 1,261 & Tinggi \\
\hline 14 & K10 Studi ke-2 & 1,696 & Sangat Tinggi \\
\hline 15 & K10 Studi ke-3 & 1,080 & Tinggi \\
\hline 16 & K11 & 0,963 & Tinggi \\
\hline 17 & K12 & 0,517 & Sedang \\
\hline 18 & K13 & 2,343 & Sangat Tinggi \\
\hline 19 & K14 & 0,316 & Rendah \\
\hline & Rata-rata & $\mathbf{0 , 9 9 4}$ & Tinggi
\end{tabular}

Summary effect yang diperoleh dikategorikan tinggi, yaitu sebesar 0,994 dengan p-value $<0,001$ dan standar deviasi error sebesar 0,134 sehingga dapat diinterpretasikan bahwa implementasi pendekatan saintifik memiliki dampak yang signifikan terhadap pembelajaran IPA di Indonesia dan pendekatan ini sesuai dengan karakteristik dan tujuan pembelajaran IPA di Indonesia.

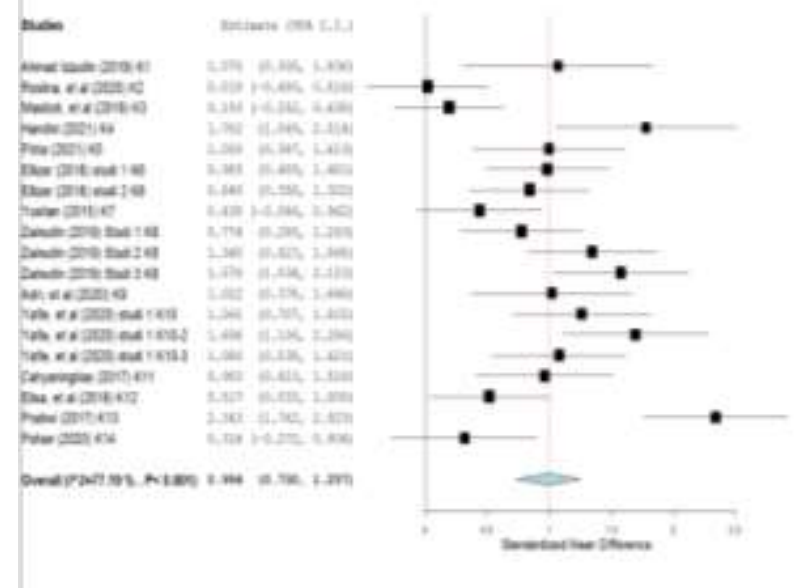

Gambar 2. Forrest Plot Implementasi Pendekatan Saintifik dalam Pembelajaran IPA 
394 Implementasi Pendekatan Saintifik dalam Pembelajaran IPA di Indonesia : Suatu Meta-Analisis Mega Elvianasti, Lufri, Asrizal, Rikizaputra

DOI: https://doi.org/10.31004/edukatif.v4i1.1819

Gambar di atas mendeskripsikan sebaran dari ukuran dampak masing-masing studi. Terdapat dua kutub, yaitu kutub/sisi kiri menunjukkan capaian kelas kontrol lebih baik jika dibandingkan dengan kelas eksperimen. Akan tetapi, pada gambar 2 tidak ada sebaran pada sisi tersebut hanya pada kutub/sisi kanan sehingga dapat diinterpretasikan bahwa capaian kelompok eksperimen lebih baik jika dibandingkan dengan kelompok kontrol. Hal ini menunjukkan bahwa implementasi pendekatan saintifik untuk kelas eksperimen di Indonesia sangat efektif untuk diterapkan dalam pembelajaran IPA.

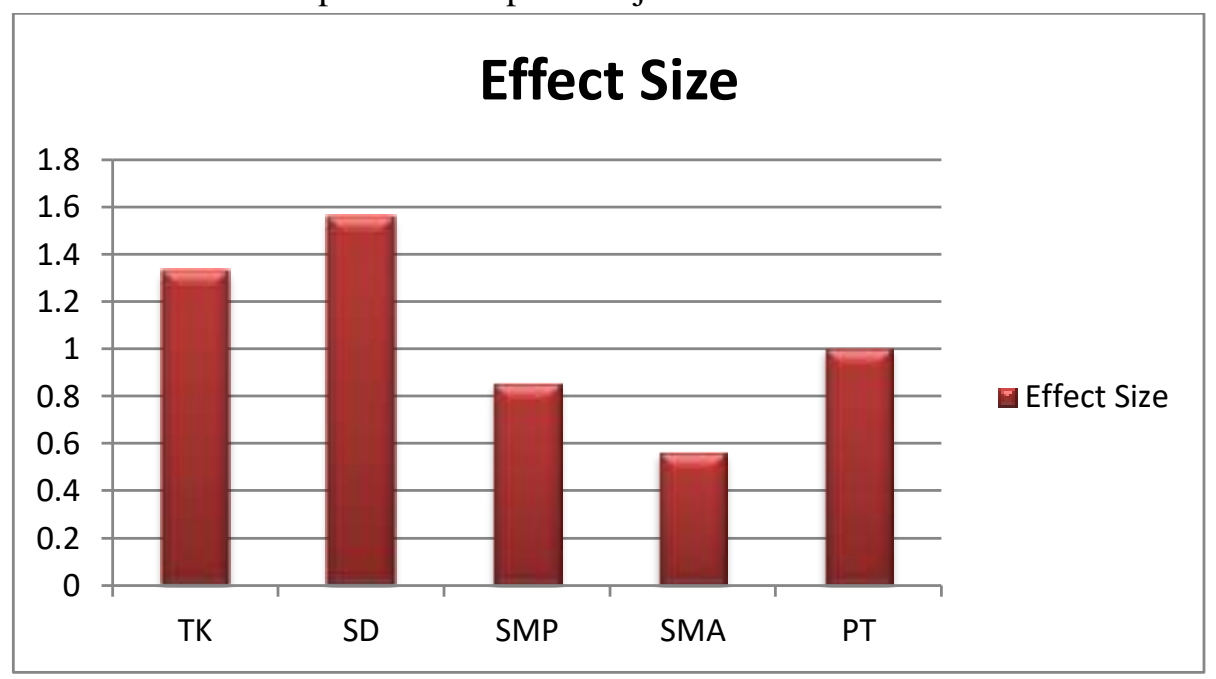

Gambar 3. Effect size berdasarkan tingkat pendidikan

ES pada tingkat pendidikan taman kanak-kanak dan sekolah dasar berada pada kategori sangat tinggi dengan ES rata-rata sebesar 1,330 dan 1,562 karena pendekatan ini mendukung anak-anak dalam membangun konseptual karena pada setiap tahap anak menggunakan berbagai keterampilan untuk menemukan informasi baru tentang suatu konsep. Selain itu, Hong \& Diamond (2012) memberikan bukti bahwa anak-anak usia TK dapat mempelajari konsep sains dan memiliki keterampilan pemecahan masalah ilmiah yang sesuai dengan usia ketika diberikan bimbingan dan instruksi yang tepat. Pendidikan sains memiliki kekuatan dalam mendukung perkembangan anak-anak dalam konteks yang bermakna sehingga harus diberdayakan untuk terlibat dalam sains (Gerde et al., 2013). Menurut Gelman \& Brenneman (2004) pendekatan saintifik adalah proses tanya jawab yang menggunakan prosedur tertentu. Proses ini dapat dijadikan pedoman untuk menciptakan pengalaman sains yang komprehensif dan bermakna bagi anak usia dini (TK). Dari gambar 3 di atas menunjukkan bahwa pendekatan saintifik cocok diterapkan pada semua jenjang pendidikan, namun memiliki ukuran dampak besar pada jenjang TK dan sekolah dasar. Implementasi pendekatan saintifik berpengaruh lebih tinggi jika diujikan pada siswa kelas rendah di sekolah dasar dibandingkan siswa yang berada pada kelas tinggi (Putri, 2020).

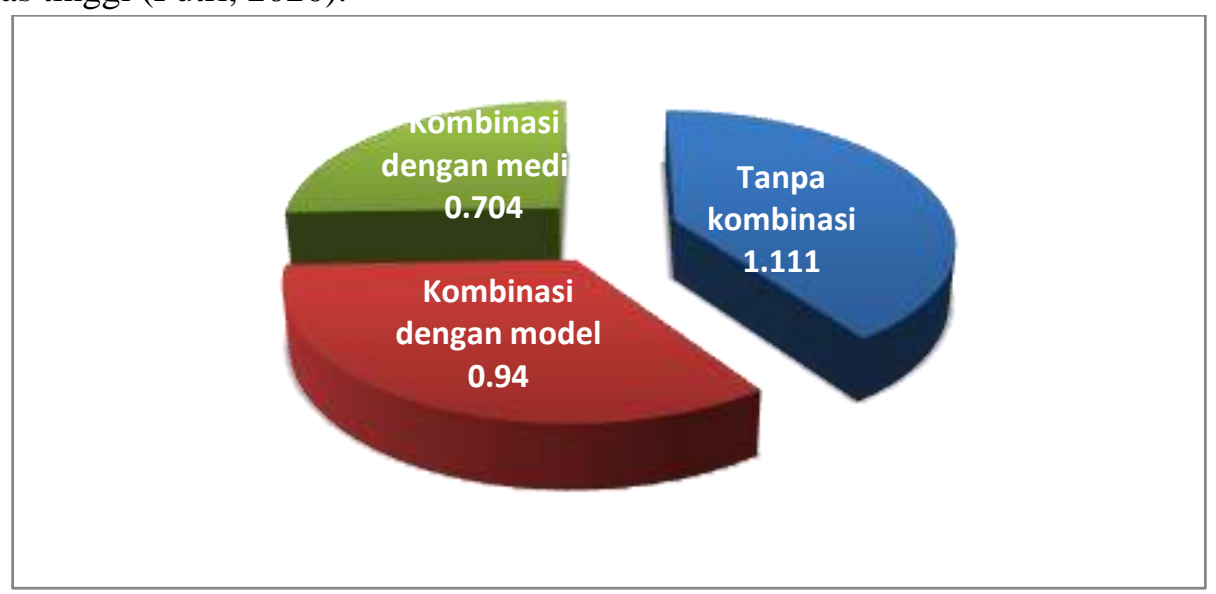

Gambar 4. Effect size berdasarkan tipe kombinasi pembelajaran

Edukatif : Jurnal Ilmu Pendidikan Vol 4 No 1 Tahun 2022 p-ISSN 2656-8063 e-ISSN 2656-8071 
395 Implementasi Pendekatan Saintifik dalam Pembelajaran IPA di Indonesia : Suatu Meta-Analisis Mega Elvianasti, Lufri, Asrizal, Rikizaputra

DOI: https://doi.org/10.31004/edukatif.v4i1.1819

Pembelajaran IPA memiliki karakteristik tersendiri jika dibandingkan dengan disiplin ilmu yang lain sehingga guru harus memilih model pembelajaran dan media yang sesuai dengan konten IPA. Hal ini bertujuan agar siswa dapat meningkatkan kemampuan atau keterampilan sainsnya. Salah satu cara yang dapat diterapkan oleh guru yaitu dengan mengombinasikan pendekatan dengan model atau media pembelajaran. Pada gambar di atas terlihat bahwa pendekatan saintifik dapat di implementasikan langsung karena dalam pendekatan saintifik sudah menggunakan serangkaian proses ilmiah. Selain itu, pendekatan saintififik dapat dikombinasikan dengan model pembelajaran. Menurut Ikhsan \& Hadi, (2018) pendekatan saintifik cocok disandingkan dengan model pembelajaran yang dapat mengaktifkan siswa, yaitu : problem based learning (Pratama et al., 2018), project based learning, dan discovery learning (Rudyanto, 2016). Selain itu model inkuiri juga cocok digunakan dalam mendukung implementasi pendekatan saintifik (Handriani et al., 2017). Selain dengan model pembelajaran, pendekatan saintifik juga dapat diimplementasikan dengan penggunaan media pembelajaran yang dapat membantu siswa dalam menguasai konsep. Tujuan pembelajaran IPA dapat tercapai apabila proses pembelajaran dipahami oleh peserta didik. Dalam memahami konsep IPA, siswa dapat mengamati fenomena-fenomena dan kejadian yang terjadi di alam dan lingkungan sekitarnya melalui langkahlangkah kerja sains. Pengalaman belajar dapat diwujudkan melalui penggunaan pendekatan pembelajaran serta berbagai media pembelajaran yang berpusat pada siswa (Syahroni et al., 2016).

Tabel 3. Effect Size berdasarkan keterampilan sains

\begin{tabular}{cccc}
\hline $\begin{array}{c}\text { Keterampilan } \\
\text { Sains }\end{array}$ & Kode Artikel & ES rata-rata & Kategori \\
\hline Berpikir kritis & $\mathrm{K} 1, \mathrm{~K} 7, \mathrm{~K} 9, \mathrm{~K} 14$ & 0,656 & Sedang \\
\hline Konseptual & $\begin{array}{c}\mathrm{K} 2, \mathrm{~K} 4, \mathrm{~K} 5, \mathrm{~K} 6, \\
\mathrm{~K} 12, \mathrm{~K} 13\end{array}$ & 1,048 & Tinggi \\
\hline Kreativitas & $\mathrm{K} 3, \mathrm{~K} 8$ & 0,960 & Tinggi \\
\hline Kognitif & $\mathrm{K} 10-1,2$ & 1,466 & Sangat Tinggi \\
\hline $\begin{array}{c}\text { Pemecahan } \\
\text { masalah }\end{array}$ & $\mathrm{K} 10-3$ & 1,080 & Tinggi \\
\hline KPS & $\mathrm{K} 11$ & 0,963 & Tinggi \\
\hline
\end{tabular}

Pembelajaran dengan menggunakan pendekatan saintifik membuat siswa terlibat secara langsung dan memfasilitasi siswa untuk dapat mengaitkan materi pembelajaran dalam kurikulum dengan situasi kehidupan nyata yang mereka hadapi sehingga siswa dapat mengembangkan kreatifitas, inovatif, dan mampu menghasilkan gagasan yang luar biasa dalam memecahkan masalah (Parmin dkk., 2016; Timeless, Assaat \& Pujiastuti 2017; Nagl, Obadovic \& Segedinac 2012; Firman; Baedhowi; Wiedy Murtini, 2018).

Pada tabel di atas effect size pada aspek kognitif dikategorikan sangat tinggi karena pada artikel yang telah dianalisis menunjukkan perbedaan yang signifikan antara kelas kontrol dan kelas eksperimen. Proses pembelajaran yang mengimplementasikan pendekatan saintifik dapat melibatkan ranah kognitif (pengetahuan), ranah afektif (sikap) dan ranah psikomotorik (keterampilan). Menurut Reif (1981) pendekatan saintifik tidak hanya berupa wawasan dan metode baru tetapi dapat menawarkan prospek realistis untuk mengembangkan keterampilan kognitif siswa. Pembelajaran tersebut bertujuan untuk mengaktifkan dan menumbuhkan kreativitas siswa (Dyers, J.H. et al ; Machali et al., 2016) menunjukkan bahwa hampir dua per tiga kemampuan kreativitas dapat dikembangkan dalam pendidikan dan selebihnya berasal dari genetik. Sehingga implementasi pendekatan saintifik dalam pembelajaran dipercaya dapat membangun kreativitas siswa (Yuliani et al., 2017). Selain itu, pendekatan saintifik dapat menunjukkan perbedaan hasil belajar siswa pada keterampilan proses sains siswa dibandingkan dengan penggunaan metode ceramah dan diskusi 
(Prasasti, 2018). Menurut Hernawati et al. (2018) menggunakan pendekatan saintifik dapat meningkatkan dan mengembangkan kemampuan akademik mahasiswa serta efektif dalam meningkatkan keterampilan proses sains siswa. Hal ini sejalan dengan penelitian Rahardjo (2019) bahwa pendekatan saintifik dapat meningkatkan keterampilan proses sains anak usia dini apabila menggunakan benda nyata sehingga siswa dapat mengamati dan mengekplorasi benda tersebut secara langsung. Keterampilan proses sains merupakan keterampilan yang berorientasi pada proses IPA, siswa secara aktif terlibat secara terarah untuk menemukan suatu prinsip atau teori, dan dapat mengembangkan teori yang sudah ada sebelumnya atau menolak suatu penemuan (Trianto, $2013: 144$ ).

\section{KESIMPULAN}

Pendekatan saintifik merupakan salahsatu strategi dalam pembelajaran IPA yang bertujuan untuk membantu siswa secara aktif mengontruksi pengetahuan berdasarkan kegiatan ilmiah. Penelitian ini menujukkan implementasi pendekatan saintifik dalam pembelajaran IPA memiliki dampak yang signifikan. Sehingga penelitian ini dapat menjadi rujukan bagi pendidik bahwa pendekatan saintifik sesuai dengan karakteristik siswa di semua tingkat pendidikan sekolah dan merupakan wujud dari implementasi kurikulum 2013.

\section{DAFTAR PUSTAKA}

Anwar, R. (2014). Hal-Hal Yang Mendasari Penerapan Kurikulum 2013. Humaniora, 5(1), 97. Https://Doi.Org/10.21512/Humaniora.V5i1.2987

Aulia, J., Permana P, N. D., Zarkasih, Z., \& Nova, T. L. (2020). Meta-Analisis Pengaruh Penerapan Pendekatan Saintifik Berbantuan Komik Terhadap Hasil Belajar Ipa Siswa Smp. Journal Of Natural Science And Integration, 3(1), 70. Https://Doi.Org/10.24014/Jnsi.V3i1.9617

Banas, J. A., Rains, S. A., Banas, J. A., \& Rains, S. A. (2016). A Meta-Analysis Of Research On Inoculation Theory A Meta-Analysis Of Research On Inoculation Theory. 7751(March). Https://Doi.Org/10.1080/03637751003758193

Cohen, P. A. (1981). Student Ratings Of Instruction And Student Achievement: A Meta-Analysis Of Multisection Validity Studies. Review Of Educational Research, 51(3), 281-309. Https://Doi.Org/10.3102/00346543051003281

Firman; Baedhowi; Wiedy Murtini. (2018). International Journal Of Active Learning The Effectiveness Of The Scientific Approach To Improve Student Learning Outcomes. International Journal Of Active Learning, 3(2), 86-91. Http://Journal.Unnes.Ac.Id/Nju/Index.Php/Ijal\%0athe

Gelman, R., \& Brenneman, K. (2004). Science Learning Pathways For Young Children. Early Childhood Research Quarterly, 19(1), 150-158. Https://Doi.Org/10.1016/J.Ecresq.2004.01.009

Gerde, H. K., Schachter, R. E., \& Wasik, B. A. (2013). Using The Scientific Method To Guide Learning: An Integrated Approach To Early Childhood Curriculum. Early Childhood Education Journal, 41(5), 315323. Https://Doi.Org/10.1007/S10643-013-0579-4

Gurevitch, J., Koricheva, J., Nakagawa, S., \& Stewart, G. (2018). Review Meta-Analysis And The Science Of Research Synthesis. Nature Publishing Group, 555(7695), 175-182. Https://Doi.Org/10.1038/Nature25753

Handriani, L. S., Harjono, A., \& Doyan, A. (2017). Pengaruh Model Pembelajaran Inkuiri Terstruktur Dengan Pendekatan Saintifik Terhadap Kemampuan Berpikir Kritis Dan Hasil Belajar Fisika Siswa. Jurnal Pendidikan Fisika Dan Teknologi, 1(3), 210. Https://Doi.Org/10.29303/Jpft.V1i3.261

Hernawati, D., Amin, M., Irawati, M. H., Indriwati, S. E., \& Omar, N. (2018). The Effectiveness Of Scientific Approach Using Encyclopedia As Learning Materials In Improving Students' Science Process Skills In 
397 Implementasi Pendekatan Saintifik dalam Pembelajaran IPA di Indonesia : Suatu Meta-Analisis Mega Elvianasti, Lufri, Asrizal, Rikizaputra

DOI: https://doi.org/10.31004/edukatif.v4i1.1819

Science. Jurnal Pendidikan Ipa Indonesia, 7(3), 266-272. Https://Doi.Org/10.15294/Jpii.V7i3.14459

Hong, S. Y., \& Diamond, K. E. (2012). Two Approaches To Teaching Young Children Science Concepts, Vocabulary, And Scientific Problem-Solving Skills. Early Childhood Research Quarterly, 27(2), 295305. Https://Doi.Org/10.1016/J.Ecresq.2011.09.006

Hwang, G. J., Tsai, C. C., Chu, H. C., Kinshu, \& Chen, C. Y. (2012). A Context-Aware Ubiquitous Learning Approach To Conducting Scientific Inquiry Activities In A Science Park. Australasian Journal Of Educational Technology, 28(5), 931-947. Https://Doi.Org/10.14742/Ajet.825

Ikhsan, K. N., \& Hadi, S. (2018). Implementasi Dan Pengembangan Kurikulum 2013. In Jurnal Edukasi (Ekonomi, Pendidikan Dan Akuntansi) (Vol. 6, Issue 1, P. 193). Https://Doi.Org/10.25157/Je.V6i1.1682

Imanuel, S. A. (2015). Vox Edukasi Vol 6, No 2 Nopember 2015 Imanuel S.A. ,. 6(2).

Lazányi, K. R. (2012). Study For Nothing? Literature Overview Of Labour Market Opportunities For Individuals With Tertiary Education. Proceedings Of Fikusz'12 Symposium For Young Researchers, 1991, 37-45.

Machali, I., Islam, U., Sunan, N., \& Yogyakarta, K. (2016). Kebijakan Perubahan Kurikulum 2013 Dalam Menyongsong Indonesia Emas Tahun 2045. September 2014. Https://Doi.Org/10.14421/Jpi.2014.31.7194

Nahdi, D. S., Yonanda, D. A., \& Agustin, N. F. (2018). Upaya Meningkatkan Pemahaman Konsep Siswa Melalui Penerapan Metode Demonstrasi Pada Mata Pelajaran Ipa. 4(2).

Prasasti, P. A. T. (2018). Efektivitas Scientific Approach With Guided Experiment Pada Pembelajaran Ipa Untuk Memberdayakan Keterampilan Proses Sains Siswa Sekolah Dasar. Profesi Pendidikan Dasar, 1(1), 16. Https://Doi.Org/10.23917/Ppd.V1i1.3623

Pratama, L. D., Lestari, W., \& Jailani, J. (2018). Implementasi Pendekatan Saintifik Melalui Problem Based Learning Terhadap Minat Dan Prestasi Belajar Matematika (Implementation Of Scientific Approach With Pbl On Interest And Achievement In Mathematics). Jmpm: Jurnal Matematika Dan Pendidikan Matematika, 3(1), 11.

Putri, K. E. (2020). Meta Analisis: Pendekatan Saintifik Terhadap Hasil Belajar Siswa. Jurnal Pendidikan Dasar Nusantara, 6(1), 127-135. Https://Doi.Org/10.29407/Jpdn.V6i1.14559

Rahardjo, M. M. (2019). Implementasi Pendekatan Saintifik Sebagai Pembentuk Keterampilan Proses Sains Anak Usia Dini. Scholaria: Jurnal Pendidikan Dan Kebudayaan, 9(2), 148-159. Https://Doi.Org/10.24246/J.Js.2019.V9.I2.P148-159

Reif, F. (1981). Teaching Problem Solving-A Scientific Approach. The Physics Teacher, 19(5), 310-316. Https://Doi.Org/10.1119/1.2340790

Rudolph, J. L. (N.D.). Epistemology For The Masses: The Origins Of “ The Scientific Method " In American Schools. 45(01).

Rudyanto, H. E. (2016). Model Discovery Learning Dengan Pendekatan Saintifik Bermuatan Karakter Untuk Meningkatkan Kemampuan Berpikir Kreatif. Premiere Educandum: Jurnal Pendidikan Dasar Dan Pembelajaran, 4(01), 41-48. Https://Doi.Org/10.25273/Pe.V4i01.305

Trianto. 2013. Mendesaign Model Pembelajaran Inovatif Progresif. Jakarta: Kencana

Syahroni, M. W., Dewi, N. R., \& Kasmui. (2016). The Effect Of Using Digimon (Science Digital Module) With Scientific Approach At The Visualization Of Students' Independence And Learning Results. Jurnal Pendidikan Ipa Indonesia, 5(1), 116-122. Https://Doi.Org/10.15294/Jpii.V5i1.5800

Wallace, B. C., Lajeunesse, M. J., Dietz, G., Dahabreh, I. J., Trikalinos, T. A., Schmid, C. H., \& Gurevitch, J. (2017). Openmee: Intuitive, Open-Source Software For Meta-Analysis In Ecology And Evolutionary Biology. Methods In Ecology And Evolution, 8(8), 941-947. Https://Doi.Org/10.1111/2041-210x.12708 
398 Implementasi Pendekatan Saintifik dalam Pembelajaran IPA di Indonesia : Suatu Meta-Analisis Mega Elvianasti, Lufri, Asrizal, Rikizaputra

DOI: https://doi.org/10.31004/edukatif.v4i1.1819

Wijayanti, A. (2014). Pengembangan Autentic Assesment Berbasis Proyek Dengan Pendekatan Saintifik Untuk Meningkatkan Keterampilan Berpikir Ilmiah Mahasiswa. 3(2), 102-108.

Yuliani, H., Yulianti, R., \& Herianto, C. (2017). Keterampilan Berpikir Kreatif Pada Siswa Sekolah Menengah Di Palangka Raya Menggunakan Pendekatan Saintifik. 